$\begin{gathered}\text { EPiC Series in Education Science } \\ \text { Volume 1, 2017, Pages 46-53 }\end{gathered}$
$\begin{gathered}\text { AUBEA 2017: Australasian Universities Build- } \\ \text { ing Education Association Conference 2017 }\end{gathered}$

\title{
Integrating Interdisciplinary Thinking and Practice: A Case Study of a Victorian University in Australia
}

\author{
Usha Iyer-Raniga ${ }^{1}$ \\ ${ }^{1}$ Deputy Head International \\ School of Property, Construction and Project Management, RMIT University. \\ Usha.Iyer-Raniga@rmit.edu.au
}

\begin{abstract}
The value of interdisciplinary approaches to curriculum have been considered successful along multiple fronts; including reducing administrative burden from inter departmental collaboration, providing "intellectual" solutions to problems and breaking academic discipline boundaries. Criticism from industry often focuses on educators not preparing graduates for work in the real world. A major reason underpinning this criticism is that the students are not exposed to the requisite skills to make them workready. Despite the pressures to include interdisciplinary approaches from an ethical perspective, putting it into practice is difficult. This paper presents the findings of involving students from three different schools from a Victorian university in Australia: built environment, business and computer science. The project was developed as part of a state government competitive fund where industry, staff and students worked together to support each other and realize mutual benefits. The aim of the study was to develop an approach involving students in a theory-practice model of a real world project by selecting a building within the university as a case study to arm students with real world knowledge focusing on sustainability outcomes. The objective was to assist in preparing students from different disciplines for better workplace experiences, where they can bring in interdisciplinary thinking and practice into their day-day operations. The outcomes for the university, in using this building as a living laboratory, was to capture lessons learned through the process of improving future building developments from a sustainability perspective. Student involvement was successful, but true interdisciplinary engagement was not achieved.
\end{abstract}




\section{Introduction}

The aim of interdisciplinary teaching is to provide real world context for delivering the aims of education. This is underpinned by the knowledge that establishing good working relationships are critical for any project success, leading to greater client satisfaction and a more positive experience for all disciplines.

This project sought to bring students from three disciplines: Construction Management, Business and Information Technology, and Computer Science to work on a common project for student engagement as part of their learning journey at the university with a view to exposing them to the real world context and explore interdisciplinary engagement and understanding in the process to make them better prepared to the world of work. The outcome of the interdisciplinary engagement was to examine if a green building on campus set out to achieve triple bottom line sustainability outcomes. Undergraduate students from final year in construction management, and business and IT worked with Masters students from computer science to explore their own discipline related knowledge while being mindful of other discipline related students and their contributions to the overall project. The project was premised on engaging students in interdisciplinary thinking and practice. The focus of the project was an iconic green building on campus. It engaged students in understanding whether this green building was indeed achieving its claims.

This paper commences with a description of the project and its approach. The underlying conceptual frameworks are then described followed the results and discussions, and conclusions

\section{The Project and approach}

In the recent past, and even most recently, the focus of employers has shifted from purely technical or professional skills in various sectors in Australia. Employer perspectives on work trials and work experience indicate that they are looking for employees with 'an interest in the industry and personal attributes such as good communication skills, a willingness to listen and learn, a positive attitude and good work ethic' (Department of Employment, Australian Government 2017). This was highlighted in the year this research project was undertaken, and formed the background for the research project.

With the above employment situation in mind, the project was guided by an interdisciplinary framework, and using a case study approach. The underlying framework in guiding the case study approach is the value of interdisciplinary engagement and the opportunity of using a university building for student learning as well as identifying where building improvements may be made. As the university is situated in an urban campus committed to the practice of incorporating sustainability principles and practices into learning and teaching, research and operational activities, an opportunity was presented in using the campus buildings for teaching and learning. These have been discussed further in the following sections of the paper.

This project was funded by a Victorian state department in Australia, interested in supporting student engagement in the real world. The grant was awarded through a competitive process and the entire project lasted the final academic semester. The project team consisted of investigators/teachers from the disciplines of construction management, computer science and business with attendant students also from these disciplines. The total number of students were seventeen: five in construction management, six each in business and computer science.

Key stakeholders, who were involved in the planning, design, construction and operation/use of the building, were invited to participate in the project. The role of the stakeholders was to guide the students in engaging with their projects and mentor them. In consultation with the building manager, eight spaces were selected for study across the building. These were the main spaces that all the 
students focused on, however, each cohort of students focused on the problem within their own disciplinary boundary. Assessments were separate for each of the student cohorts and the course was not redesigned to meet specific learning outcomes.

Students were brought together formally three times during the semester for this project as a group. The first time was to introduce the industry stakeholders also acting as mentors for the students. This provided an opportunity to describe the overall aims of the project and respond to specific questions on the spaces selected for study. The second formal workshop was half way through the project, when the students presented initial findings for feedback from the stakeholders. The final presentation was at the end of the semester, when final assessments for the project was due. Beyond these formal meetings, students interacted with their own teachers in the different schools and sought advise as required in the development of their own projects and to meet their course learning outcomes. Students were encouraged to meet students from the other disciplinary cohorts as the semester progressed.

This paper reports the overall outcomes resulting from stakeholder engagement, student interactions, assessments, course and program learning outcomes and teacher participation. Construction management students used the building to focus on understanding thermal comfort in selected areas of the building, while the business students focused on the user needs and value of the selected spaces in the building through surveys. The computer science students used online surveys for creating an application focused on understanding the user interaction in the space and satisfaction. There were some overlaps between the three groups of students. Broader outcomes of the research were to assist the University to improve future building developments, along with creating a living case study for integration into student curriculum.

The underlying conceptual frameworks of this project are briefly described below.

\section{Interdisciplinary engagement}

The context for this study comes from the nature of the built environment discipline itself. The built environment disciplines focus on the application of applied knowledge. There is no single built environment discipline, by its very nature; the built environment comprises a range of disciplines. There has also been lack of a theoretical disciplinary base for the built environment (Chynoweth, 2009; Yocom et al 2012). Chynoweth argues that the built environment is in fact, not a discipline in the true sense and requires the built environment academic community to develop a common epistemological axiomatic to make it truly interdisciplinary.

The outcomes of interdisciplinary teaching and learning is linked with contextualised, applied and transdisciplinary knowledge whereas discipline based research is pure, discipline specific and often has a complex and rich history (Manathunga et al, 2006). Interdisciplinary teaching and learning can be applied at both undergraduate and postgraduate programmes and there may be an argument to say that all post graduate programmes should be interdisciplinary if they are to have any real world applications.

Accompanied with interdisciplinary are other related terms: transdisciplinary, multidisciplinary, pluridisciplinary and crossdisciplinary. While debates still exist about interpretations, there are some common understandings across the literature (Chynoweth, 2009; Manathunga et al 2006, and built on the works of Grigg $(1999,2003)$ and Jantsch, 1972). Transdisciplinary engagement establishes a common system of concepts and understanding for a set of disciplines. In multidisciplinary engagement, several disciplines may be used simultaneously and possible relations between them may not be made explicit. It is characterized by an additive approach, rather than synthesis between the disciplines. In pluridisciplinary engagement, there is a deliberate juxtaposition of different disciplines to enhance relationships. In crossdisciplinary engagement, in addition to the juxtaposition is the 
deliberate attempt to coordinate the relationship between the different disciplines. It is quite possible that one discipline may deliberately impose its own disciplinary concepts and axiomatic. The relationships between the disciplines are not characterized by collaboration, dialogue and relationships, but more about control.

Academic engagement for supporting interdisciplinary teaching is critical. Callaghan (2015) used reflective collaboration to support various disciplinary contexts in the engineering, built sciences and information science educational disciplines. The three-year process of reflective collaboration found that dialogue, critique and reflection supported transformation of challenges into learning opportunities for the teachers. Student outcomes resulting from interdisciplinary learning are: curiosity, respect, openness, patience, diligence, self-regulation, social experiences, and educational experiences.

One of the earliest examples of interdisciplinary education in Australia is the case study of Griffith University with over four decades of interdisciplinary teaching and learning (Franks et al 2007). Queensland University of Technology (QUT) also reported the use of an interdisciplinary collaborative and teaching project within the faculty of built environment and engineering focusing on sustainable development to facilitate creative teaching and learning (Shanableh et al 1998).

Recognising that interdisciplinary engagement in the built environment disciplines is important has also been reported (Wood, 1999). Interviews with senior academics in his paper showed that academics favoured multidisciplinary project work to foster a more collaborative approach to interdisciplinary working. In another example of using studio education in the planning and design disciplines in the USA, the authors noted the importance of collective understanding and sharing disciplinary vocabulary to improve students' communicative techniques (Yocom et al 2012).

In this paper, interdisciplinary focuses on the additive learning outcomes gained not just through the course learning outcomes of the various Schools involved, but also an overall outcome of enhancing students' higher order thinking and cognitive skills. In other words, while the course learning outcomes were focused on Mode 1 (discipline specific), the engagement across different schools also sought to achieve Mode 2 (transdisciplinary aligned with real world outcomes) (Gibbons et al 1994, Manathunga et al 2006).

There are barriers to interdisciplinary teaching and research (Franks et al, 2007). The shift from discipline based knowledge to more integrated approaches is beyond the comfort zones of most academics. Communication is critical so there is shared understanding and relationships developed between the various discipline based academics. It is also difficult to publish interdisciplinary work. Innovation in education has mostly been linked to technology, but innovation can also be applied in teaching and learning in an interdisciplinary environment (Dima, 2013).

\section{University campuses as living laboratories}

Universities can be used as a living laboratory or lab to achieve triple bottom line outcomes for the university, whilst using campus assets as a part of student education. Living labs constitute a form of experimental governance, where stakeholders develop and test new technologies and ways of living to address the challenges of climate change and urban sustainability. Applied research undertaken in the real world offer a framework to not only connect students to applied research, it also offers the opportunity to bring a range of stakeholders together to work collectively to solve a common problem. In the process of coproduction novel and innovative approaches can be trialed in often nonthreatening environments leading to new sustainability technologies and services. One of the key considerations of coproduction implies collaborative efforts across sectors as well as between disciplines so that the resulting solutions are truly holistic in nature, essential to address sustainability challenges. 
Lack of coordinated approaches to engaging in interdisciplinary approaches have been highlighted by Filho et al (2015). Evans et al (2015) note the importance of engaging with non academic teaching staff, and Elliott and Wright (2013) discuss the importance of student engagement. Other authors such as Capdevila et al (2002) have shown that integrating research and education is essential for success. Muller-Christ et al (2014) report on the importance of the 3Cs: Campus, Curriculum and Community for putting sustainability into practice. Campuses may be used to engage all members in sustainability practice throughout the university, curriculum changes offer a window of opportunity to bring theory and practice within universities together and communities can be formed within the universities itself, creating role models of engagement.

Using the case study of business schools Painter-Morland et al (2016) discuss the importance of adding 'systemic institutional integration' to integrating sustainability in business education and management. These are 'piggy backing', digging deep', 'mainstreaming' or 'focusing'. Piggy backing refers to inclusion of sustainability integration to individual courses such as guest lecturing. Digging deep is about integrating sustainability through new stand alone modules which may be electives. Mainstreaming integrates sustainability within existing structures with emphasis on broader cross curricular perspectives for the entire program. Focusing is about the integration of sustainability through new crossdisciplinary offerings such as sustainability related courses and other new offerings. Systemic institutional integration comprises of leadership and capacity building across schools.

There are limitations as to why green buildings are not mainstream in university campuses (Richardson et al 2007). Empowerment of university leaders and staff to catalyse and implement new paradigms for sustainability have been noted as a key reason by these authors and others (Lozano et al 2013). While the literature is focused mostly on success stories rather than on failures, lack of transparency of failures impedes overall understanding of learning outcomes (Velazquez et al 2005). There is no one recipe or approach for the successful implementation of sustainability programs across the world. Yet, despite this as has been evidenced from this section; sustainability initiatives across university curricula and campuses are flourishing.

\section{Results and discussions}

As already indicated, the courses in each of the schools considered were not restructured. Course learning outcomes remained the same, however, all students examined spaces within the green building in their study to assess and understand overall, whether triple bottom line sustainability was achieved through their own disciplinary boundaries. Assessments remained within the course learning outcomes in the disciplinary boundaries. However, students engaged with others to understand whether the building was comfortable to work in and what were the key areas for improvement in the building.

External stakeholder engagement with the building manager, architect and specialist consultant was successful. They assisted the project team in determining the spaces to be studied. Enthusiasm by the internal stakeholders; facilities department of the university and program managers of the three schools was modest. The facilities department staff were only interested in issues requiring maintenance. The program managers of the three schools were not interested in the underlying interdisciplinary concept of why the project was spread across three schools. A very senior learning and teaching academic supported the project, remarking that the project lead had accomplished a great feat by 'involving staff, students and industry across three schools in three distinctive areas of the university'.

Teacher participation varied. Where the course coordinators were also the investigators involved in the project, coordination and support for the project itself resulted in better teamwork. Where the course coordinator was not the teacher involved in the project, shared ownership and goals were more 
difficult. In computer science, this project was part of a capstone supporting the innovative outcomes for this project. The course coordinator was also the investigator, resulting in better planning, leading to a higher quality of assessment, student engagement and interaction, and follow up with students. Involving senior staff such as the Dean/Head of School across the three schools would have assisted in securing the top-down support, a critical factor that the literature has also noted.

Student interactions varied. The interaction between the students of the various disciplines were limited. Students within the same schools interacted more with each other. On probing this further, it was found that timetabling, assessment scheduling and such other practical matters prevented students from engaging with each other beyond the project itself. The overall observations made by the three cohort of students in the study of the building are presented below.

Areas studied in the building including learning spaces. Of all spaces studied in the building, student portals were the most liked places compared to the lecture theatre selected for the study. This is not surprising as the project building's occupation patterns by students surpassed university expectations. Students observed that this green building had a very different layout of rooms compared to other spaces on campus. Students found it easier to communicate with each other as a result of good design and room layout and felt that learning outcomes were realised, leading to less stress. However, room layouts were not necessarily conducive always to communication where eye contact could be maintained. There were situations where the room layout presented the speaker's back to the class. Placement of air vents under the chairs were also not the most effective way to dispense air circulation in the space, as few students felt quite cold at the end of the class. Use of the white board was not always successful due to technological difficulties.

With respect to common spaces, students complained of glare in these spaces. Some students preferred a designated quiet study area. However, these did not work particularly well as the acoustic separation was still a problem in the quiet study spaces. Students indicated that there were not enough power outlets. Over ninety percent of students using the study area were observed to be using an electronic device and it was critical to provide more such spaces with appropriate functional support to facilitate student learning outcomes. Some spots in the building also had poor internet connectivity, which was a cause of frustration for students. Unsatisfactory air flow in the café spaces studied, student hub, and some student portals and common areas were also reported, making the space quite uncomfortable to be in for long periods of time.

Coordination of the student and staff mentors, including the industry stakeholders was a logistical nightmare. Students' timetables invariably clashed, as did that of the lecturers. Considering the stakeholders provided their time for free, their commitment to the project was very high as demonstrated with their engagement with students.

\section{Conclusions}

This paper has shown that it is possible to use a campus project to bring three separate disciplines of staff and students to achieve triple bottom line sustainability outcomes. While there were many areas in the building that were comfortable, there were still some areas that needed improvement, particularly from a student perspective.

Engaging with staff from the three disciplines early, including senior management support from the schools was critical to meet the outcomes of an interdisciplinary framework. However, the project was not truly interdisciplinary as intended; it was in fact, pluridisciplinary. An additive approach between the disciplines however, raised student cognitive understanding and supported their soft skills, although not explored to its full potential. Students were exposed to the real world through the project itself and engaging with the stakeholders. They worked alongside each other and were exposed to other viewpoints. Unfortunately, this could not be gleaned objectively due to timing of the 
project. For all students across the three disciplines this project was part of their final semester in their programs.

Discussions with students during the various sessions and informal discussions confirmed that the engagement with stakeholders and other students led to some interdisciplinary reflections and deliberations. True interdisciplinarity would only be achieved if the project had a common course for the three cohorts of students with common course learning outcomes. Disciplinary underpinnings were not taught or discussed and debated by students for true interdisciplinary engagement to be considered. If sustainability outcomes are the overall focus, a university needs to find a way to integrate both curriculum and research. This project has taken a step in this direction, however, further top down engagement is critical to use the overall campus as a living laboratory.

\section{Acknowledgement}

The author thanks Victorian Future Designers Grant for providing funds for the project and the project team, including stakeholders, staff and students.

\section{References}

Department of Employment, Australian Government. (2017). 'Work trials and work experience'. https://docs.employment.gov.au/node/38196, Accessed June 2017.

Callaghan, R. (2015) 'Transforming teaching challenges into learning opportunities: interdisciplinary reflective collaboration', Africa Education Review, 12:4, 599-617, DOI: 10.1080/18146627.2015.1112145.

Capdevila, I., Bruno, J., and Jofre, L. (2002). 'Curriculum greening and environmental research co-ordination at the Technical University of Catalonia', Barcelona. Journal of Cleaner Production, 10, 25-31.

Chynoweth, P. (2009). 'The built environment interdiscipline: A theoretical model for decision makers in research and teaching', Structural Survey, Vol. 27: 4, pp.301-310.

Dima, A. M. (2013). Challenges and Opportunities for Innovation in Teaching and Learning in an Interdisciplinary Environment. IGI Global.

Evans, J., Jones, R., Karvonen, A., Millard, L. And Wendler, J. (2015). 'Living labs and coproduction: university campuses as platform for sustainability science', Environmental Sustainability, $16,1-6$.

Elliott, H and Wright, T. (2013). 'Barriers to sustainable universities and ways forward: A Canadian students' perspective', The 3rd World Sustainability Forum, 1-30 November 2013.

Filho, W. L., Shiel, C., and Arminda do Paço (2015) Integrative approaches to environmental sustainability at universities: an overview of challenges and priorities, Journal of Integrative Environmental Sciences, 12:1, 1-14, DOI: 10.1080/1943815X.2014.988273.

Franks, D., Dale, P., Hindmarsh, R., Fellows, C., Buckridge, M.and Cybinski, P. (2007) Interdisciplinary foundations: reflecting on interdisciplinarity and three decades of teaching and research at Griffith University, Australia, Studies in Higher Education, 32:2, 167-185.

Gibbons, M., Limoges, C. and Nowotny, H. (1994) The new production of knowledge, London, Sage, pp. 17-45.

Grigg, L. (1999). Cross-disciplinary research: a discussion paper Canberra, Australian Research Council.

Grigg, L. (2003). Emerging issues for cross-disciplinary research Canberra, Commonwealth Department of Education, Science and Training. 
Jantsch, E. (1972). 'Towards interdisciplinarity and transdisciplinarity in education and innovation', in Apostel, L., Berger, G., Briggs, A. and Michaud, G. (Eds), Interdisciplinarity: Problems of Teaching and Research in Universities, 7-12 September 1970, OECD, Centre for Research and Innovation, University of Nice, Nice, pp. 97-121.

Lozano, R., Lukman, R., Lozano, F. J., Huisingh, D., and Lambrechts, W. (2013). Declarations for sustainability in higher education: becoming better leaders, through addressing the university system, Journal of Cleaner Production 48, 10-19, DOI:10.1016/j.jclepro.2011.10.006.

Manathunga, C., Lant P., and Mellick, G. (2006) Imagining an interdisciplinary doctoral pedagogy, Teaching in Higher Education, 11:3, 365-379, DOI: 10.1080/13562510600680954.

Muller-Christ, G., Sterling, S., van Dam-Mieras, R., Adomssent, M., Fischer, D., and Rieckmann, M. (2014) The role of campus, curriculum, and community in higher education for sustainable development - a conference report. Journal of Cleaner Production, 62, 134-137.

Painter-Morland, M., Ehsan Sabet, E., Molthan-Hill, P., Goworek, H., and de Leeuw, S. (2016). 'Beyond the Curriculum: Integrating Sustainability into Business Schools'. Journal of Business Ethics, 139:737-754, DOI: 10.1007/s10551-015-2896-6.

Richardson, G, A. and Lynes, J. K. (2007). Institutional motivations and barriers to the construction of green buildings on campus A case study of the University of Waterloo, Ontario, International Journal of Sustainability in Higher Education, Vol. 8 Iss 3 pp. 339-354

Shanableh, A., Bajracharya, B., Poirier, J., Matthews, J.A. and Meixsell-Draper, P. (1998), A Framework for Interdisciplinary Collaboration within the Faculty of Built Environment and Engineering, QUT Waves of Change Conference, Gladstone, QLD, 28-30 September 1998.

Velazquez, L., Munguia, N., and Sanchez, M. (2005),'Deterring sustainability in higher education institutions: An appraisal of the factors which influence sustainability in higher education institutions', International Journal of Sustainability in Higher Education, Vol. 6 Iss 4 pp. 383 - 391, http://dx.doi.org/10.1108/1467637051062386.

Wood, G., (1999) 'Interdisciplinary working in built environment education', Education + Training, Vol. 41 Issue: 8, pp.373-380.

Yocom, K., Proksch, G., Born, B. and Tyman, S. K. (2012) The Built Environments Laboratory: An Interdisciplinary Framework for Studio Education in the Planning and Design Disciplines, Journal for Education in the Built Environment, 7:2, 8-25. 